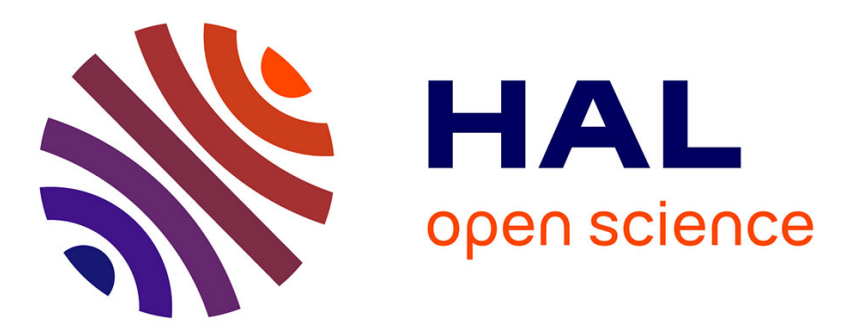

\title{
A highly-sensitive microplate fluorimetric method for the high-throughput determination of nitrate ion in aqueous compost extracts
}

Marco Ciulu, Nadia Ollivier, Carine Demelas, Jean-Luc Boudenne, Bruno Coulomb, Frédéric Théraulaz, F. Robert-Peillard

\section{To cite this version:}

Marco Ciulu, Nadia Ollivier, Carine Demelas, Jean-Luc Boudenne, Bruno Coulomb, et al.. A highlysensitive microplate fluorimetric method for the high-throughput determination of nitrate ion in aqueous compost extracts. Microchemical Journal, 2018, 138, pp.424 - 429. 10.1016/j.microc.2018.01.042 . hal-01700927

\section{HAL Id: hal-01700927 \\ https://hal.science/hal-01700927}

Submitted on 5 Feb 2018

HAL is a multi-disciplinary open access archive for the deposit and dissemination of scientific research documents, whether they are published or not. The documents may come from teaching and research institutions in France or abroad, or from public or private research centers.
L'archive ouverte pluridisciplinaire HAL, est destinée au dépôt et à la diffusion de documents scientifiques de niveau recherche, publiés ou non, émanant des établissements d'enseignement et de recherche français ou étrangers, des laboratoires publics ou privés. 
1 A highly-sensitive microplate fluorimetric method for the high-throughput determination of nitrate ion in aqueous compost extracts.

Marco Ciulu, Nadia Ollivier, Carine Demelas, Jean-Luc Boudenne, Bruno Coulomb, Frédéric Théraulaz, Fabien Robert-Peillard ${ }^{*}$

Aix Marseille Univ, CNRS, LCE, Marseille, France.

*Corresponding author: fabien.robert-peillard@univ-amu.fr

\begin{abstract}
In this paper, a new spectrofluorimetric method for the determination of nitrate in aqueous compost extracts is presented. The microplate procedure is based on the reduction of nitrate to ammonium by means of $\mathrm{Zn}$ powder under acidic conditions and the following derivatization of ammonium with o-phtaladehyde (OPA) and N-acetylcysteine (NAC) to give a fluorescent derivative. Optimization work allowed performing the reduction in $30 \mathrm{~min}$ on a small sample volume $(150 \mu \mathrm{L})$ and using a little quantity of metal $(20 \mathrm{mg})$. The use of strong acids is also avoided. Excellent limit of detection was achieved $\left(1.3 \mu \mathrm{M}=0.08 \mathrm{mg}^{-\mathrm{L}^{-1} \mathrm{NO}_{3}}{ }^{-}\right)$along with good precision levels (4.2 and $14.3 \%$ for 50 and $5 \mu \mathrm{M}$, respectively) and a satisfactory linear dynamic range $(4-100 \mu \mathrm{M})$. A good agreement between data coming from our method and from ion-exchange chromatography was found on real compost samples, indicating a good level of accuracy.
\end{abstract}

Keywords: Nitrate, microplate, compost extracts, spectrofluorimetric.

\title{
1. Introduction
}

Composting represents an useful way to recycle organic wastes into a fertilizing product. The formation of compost occurs by means of an exothermic and aerobic process promoted by micro-organisms who decompose the organic matter. The physical and chemical changes that occur during the compost formation determine the loss of the putrescebility of the biomass which also undergoes a partial mineralization [1-3]. The industrial importance of compost lies in its capability to enhance the agronomic quality of soil. Its employment in the agricultural industry has proved to be able to increase the yield of agronomic and horticultural crops and to restore soil conditions after tree harvesting [4]. Moreover, it represents a valid alternative to 
the traditional incineration and to landfills. In fact, thanks to the water loss and to the mineralization of organic matter, the global volume and mass of the initial waste products can be reduced up to $50 \%[5,6]$.

The monitoring of the composting process is essential not only to pursue a correct waste management but also to preserve the economic value of a commercial item. During the composting process nitrogen present in the biomass goes through two main mineralization phenomena: ammonification (production of $\mathrm{NH}_{4}^{+}$) and nitrification (production of $\mathrm{NO}_{3}^{-}$). Nitrogen-based parameters (i.e. concentration of ion nitrate and ammonium, and $\mathrm{NH}_{4}{ }^{+} / \mathrm{NO}_{3}{ }^{-}$ ratio) have proved to be useful to monitor the correct development of the composting process. In fact, while ammonium concentration tends to decrease during the compost stabilization, formation of nitrate is facilitated in mature compost thanks to the lower respiration rates [7]. Monitoring of nitrate in various environmental samples in the frame of the 1991 European Union Nitrates Directive [8] (which aims to protect water quality across Europe by preventing nitrates from agricultural sources polluting ground and surface waters) can also benefit from efficient analytical techniques applied to aqueous compost extracts. For these reasons, the attention of researchers and enterprises has been focused on the assessment of reliable analytical protocols aimed to quantify these chemical species in compost and compost extracts. In the past, various methods have been proposed for the quantification of nitrate ion in aqueous solutions including spectrophotometry [9, 10], fluorimetry [11, 12], ion chromatography [13] and flow injection analysis [14]. Literature also offers some examples of microplate-based procedures where nitrate is first reduced to nitrite which is later spectrophotometrically revealed after derivatization $[15,16]$. In spite of the strong contribution given by these works for the determination of nitrate, the main problem related to the cited procedures is given by the use of cadmium, which is renowned for his high toxicity, and also by the strong interferences caused by complex samples such as compost extracts, when the measurement is carried out by spectrophotometry.

The main goal of our work was to develop a new sensitive method for the determination of nitrate by a microplate-based procedure in compost aqueous extracts. In the past, our research group has developed various analytical methods based on the 96-wells technique [17-20]. In particular, a fluorescence-based microplate procedure for the quantification of ammonium and primary amines in compost water extracts and other matrices was recently assessed [17]. The basic idea for the assessment of our method was to exploit the previous protocol, reducing first the nitrate to ammonium and then quantifying the latter by means of the method already assessed. An important advantage of this analytical strategy would be the easy determination of both nitrate and ammonium ions with a single set of detection reagents (with or without the reduction step), which would be highly valuable as the $\mathrm{NH}_{4}{ }^{+} / \mathrm{NO}_{3}{ }^{-}$ratio is one of the principal nitrogen-based indicators of compost maturity [7]. 
In the last years, metals have been employed for the reduction of nitrate to nitrite or ammonia in aqueous solutions. Reducing properties of cadmium, aluminum, zinc, iron and also of some types of alloys like Devarda's alloy and Arndt's alloy have been reviewed by Fanning [21]. Among all, $\mathrm{Zn}$ seems to represent a good candidate for the reduction of nitrate to ammonium. Indeed, besides being less toxic than other metals (i.e. cadmium), it has been already successfully used under mild reduction conditions for the quantification of nitrate in water solutions and other matrices [22-24], but never for compost extracts so far. For this reason, we present in this work a new fluorescence-based microplate method for the quantification of nitrate in compost water extracts which includes the conversion to ammonium by means of $\mathrm{Zn}$ powder, and which is developed as a simple analytical tool that can be used directly in composting platforms in a non-specialized environment (no fume hoods for strong acids and non-expert technicians).

\section{Experimental}

\subsection{Samples and water extraction of organic matter}

Two type of compost samples were selected for this study. More specifically, the first type of samples (A samples) was exclusively composed by green wastes deriving from activities of gardening and maintenance of green public or private areas. Sampling sites were located in 3 private areas (agricultural lands) located in Provence Alpes-Côte d'Azur region (France, GPS coordinates : near Gardanne : 43.466350N, 5.454541E ; near Rousset : 43.468935N, $5.634117 \mathrm{E}$, and near Rougiers : $43.411657 \mathrm{~N}, 5.841994 \mathrm{E})$. Ages of the swaths were always included between one week and twelve months. It should be noticed that studied swaths can be very heterogeneous in their composition of plant species, size and height. The second type of samples (B samples) consisted in sewage sludge mixed with green wastes (1/3-2/3, v/v). In this case, samplings were performed on an industrial composting platform (Biotechna) located in Ensuès-la-Redonne (Bouches-du-Rhône, France, GPS coordinates 43.376838N, 5.190849E), A single swath was studied in a period of time included between 1 week and 6 months, with a various frequency of sampling (samplings were performed every week during the 2 first months, every two weeks the next month, and every month the three months afterwards). For each type of compost, matter was collected in different places of the swath at $80 \mathrm{~cm}$ depth, in order to get a final composite sample of $2 \mathrm{~kg}$ representative of compost. The water extractions were performed in PTFE Teflon tube (triplicates per soil sample) on an orbital shaker (Fisher Scientific Bioblock SM30B) at $125 \mathrm{rpm}$ and at room temperature. Organic matter was extracted through shaking $6 \mathrm{~g}$ of fresh compost with $60 \mathrm{~mL}$ of ultrapure water (resistivity of $18 \mathrm{M \Omega} \mathrm{cm}{ }^{-1}$ at $25^{\circ} \mathrm{C}$, and total organic carbon $<20 \mu \mathrm{g} \mathrm{L}^{-1}$ ) with a soil/water ratio of $1 / 2(\mathrm{w} / \mathrm{v})$ for $2 \mathrm{~h}$ under $\mathrm{N}_{2}$. After extraction step, the tubes were centrifuged at $8000 \mathrm{rpm}$ for 
15 min (JP SELECTA, Medifriger BL-S), and the supernatants were collected and filtered through $0.45 \mu \mathrm{m}$ membrane filters (PES membrane, Millipore, France). The resulting solutions were stored in the dark at $-18^{\circ} \mathrm{C}$ until analysis.

\subsection{Reagents and solutions}

All chemicals were of analytical reagent grade and used without further purification. Zn powder (100 mesh) and Zn granules were purchased from Alfa Aesar (Germany) and Prolabo (France), respectively. Copper granules were purchased by Fluka (France) while Fe powder (puriss., $<212 \mu \mathrm{M}$ ) and Al powder were provided by Sigma-Aldrich (France). O-phthaldehyde (OPA) was obtained from Acros Organics (Belgium) and N-acetyl-L-cysteine (NAC) from Sigma-Aldrich. Buffers solutions were prepared dissolving the proper amount of sodium acetate (Sigma-Aldrich), 4-(2-Hydroxyethyl)piperazine-1-ethanesulfonic acid (HEPES, Acros organics), anhydrous sodium carbonate (Sigma-Aldrich) and sodium tetraborate decahydrate (Sigma-Aldrich) in ultrapure water (Millipore, USA, resistivity $>18 \mathrm{M} \Omega \mathrm{cm}$ ) and adjusting the $\mathrm{pH}$ with sodium hydroxyde or hydrochloridic acid.

Stock standard nitrate solution $(0.1 \mathrm{M})$ was prepared by dissolving appropriate amount of sodium nitrate (Sigma-Aldrich) in ultrapure water. Working solutions were obtained by diluting stock solutions to proper concentrations.

\subsection{Instruments}

\subsubsection{Microplate}

Microplate fluorescence measurements were carried out on a microplate reader (Infinite M200, Tecan France SAS, France), operating at $30^{\circ} \mathrm{C}$ and controlled by i-control ${ }^{\mathrm{TM}}$ software (Tecan). Detection was performed by top fluorescence reading at $\lambda_{\mathrm{ex}}=415 \mathrm{~nm}$ and $\lambda_{\mathrm{em}}=485 \mathrm{~nm}$. Other parameters were as follows: gain: 80; number of flashes: 5; integration time: $20 \mu \mathrm{s}$. Fluorescence intensities were expressed in arbitrary units (a.u.). Polystyrene black $96 \mathrm{~V}$-well microplates (Fisher Scientific, France) were used.

\subsubsection{Ion chromatography analysis of nitrate}

Nitrate analysis was carried out by ion chromatography (EN ISO 10304-2:1996) on a ICS-3000 HPLC system (Dionex, USA), driven by Chromeleon ${ }^{\circledR}$ (6.80 version) equipped with a guard column (Dionex AG11-HC), an analytic Dionex AS11-HC (4 × $250 \mathrm{~mm})$ column, a conductimetric detector (Dionex CD-25) and using a $200 \mu \mathrm{L}$ loop injection valve. Analysis were performed in an isocratic mode $\left(22.5 \mathrm{mM} \mathrm{NaOH}\right.$ in helium sparged deionized water) at $30^{\circ} \mathrm{C}$,

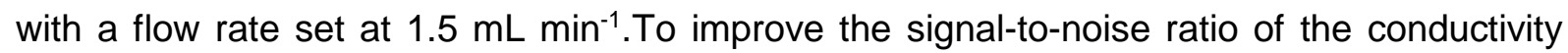


measurement, an external flow electrochemical suppressor system (ACRS $5004 \mathrm{~mm}$ ) was added to the analytical system.

\subsection{Analytical protocol for nitrate determination}

Twenty mg of $\mathrm{Zn}$ powder (100 mesh) were dispensed into the wells of the microplate, $150 \mu \mathrm{L}$ of sample or standard solution were introduced and $20 \mu \mathrm{L}$ of MES buffer $(0.1 \mathrm{M}, \mathrm{pH}$ 6) were added. The plate was shaken for $30 \mathrm{~min}$ at $30^{\circ} \mathrm{C}$. Then, $120 \mu \mathrm{L}$ of the solution were transferred into new wells where $20 \mu \mathrm{L}$ of a solution of $20 \mathrm{mM} \mathrm{NAC}$ and $30 \mu \mathrm{L}$ of $13 \mathrm{mM}$ OPA in ethanol$0.15 \mathrm{M}$ carbonate buffer $\mathrm{pH} 10.5(10: 90, \mathrm{v} / \mathrm{v})$ were subsequently added. The plate was shaken for $10 \mathrm{~min}$ and fluorescence intensity was then recorded, with excitation and emission wavelengths set at $\lambda_{\mathrm{ex}}=415 \mathrm{~nm} / \lambda_{\mathrm{em}}=485 \mathrm{~nm}$. Concentrations in unknown samples were determined using the linear calibration curves obtained with standards. Nitrate concentration was calculated after quantifying the ammonium by means of the microplate procedure previously assessed by our research group [17].

\section{Results}

\subsection{Choice of the metal system for the reduction of nitrates}

The proposed analytical procedure is based on the reduction of nitrate ion to ammonium and the subsequent determination of the latter by fluorescence (Figure 1). One of the main challenges of this work was to find a metal for the effective reduction of nitrates under mild conditions (moderate temperature to apply the developed protocol in polystyrene microplates which don't withstand high temperatures, and also because the most affordable microplate readers don't enable heating above $40^{\circ} \mathrm{C}$ ), but which does not interfere with the second step of the protocol (derivatization of ammonium with OPA/NAC and formation of isoindol adduct). Alloys like Devarda's alloy generally provide efficient reduction of nitrates, but only under quite harsh reaction conditions (i.e. boiling water). Several tests were performed in order to reduce the nitrate to ammonium with various metals. Experiments conducted with aluminum (foil ad powder) and copper (granules) at various $\mathrm{pH}$ conditions did not provide any significant result proving to be not efficient for the reduction of the analyte. On the other hand, tests performed with iron (thread and powder) revealed that this metal is able to convert nitrate to ammonium in acidic conditions (encouraging results were obtained at $\mathrm{pH} 5$ and 6). Unfortunately, the corrosion products formed during the reduction phase constituted a strong interference for the revelation of ammonium preventing a precise and accurate determination. Attempts to suppress the interference by adding EDTA at various concentration levels $(0.1-1 \mathrm{M})$ were unsuccessful. Finally, Zinc proved to be promising both for reduction of nitrate and ammonium 
derivatization under mild conditions in our first experiments, so we decided to optimize our method with this metal.

\subsection{Optimization of the analytical method with $\mathrm{Zn}$}

Reduction of nitrate with $\mathrm{Zn}$ was performed in presence of various selected buffers in order to identify the best $\mathrm{pH}$ conditions for the conversion of nitrate to ammonium and for the derivatization. These first experiments were performed by means of $\mathrm{Zn}$ granules. A quantity of metal granules large enough to entirely cover the bottom of the microplate wells was cut and introduced. $100 \mu \mathrm{L}$ of a water solution of $\mathrm{NaNO}_{3} 100 \mu \mathrm{M}$ were introduced in the wells containing the metal along with $20 \mu \mathrm{L}$ of : i) acetate buffer $(0.1 \mathrm{M}, \mathrm{pH} 5)$, ii) MES buffer $(0.1 \mathrm{M}, \mathrm{pH} 6)$, iii) HEPES buffer $(0.1 \mathrm{M}, \mathrm{pH}$ 7), iv) carbonate buffer $(150 \mathrm{mM}, \mathrm{pH} 10.5)$, v) borate buffer (100 $\mathrm{mM}, \mathrm{pH}$ 11.5). Also $\mathrm{HCl} 2.5 \mathrm{M}$ and $\mathrm{H}_{2} \mathrm{SO}_{4} 2.5 \mathrm{M}$ were tested for the reduction. In this case, $\mathrm{NaOH} 0.1 \mathrm{M}$ was added to the wells until basic $\mathrm{pH}$, before derivatization with NAC and OPA. The suspensions were shaken for $1 \mathrm{~h}$ at $30^{\circ} \mathrm{C}$ before addition of OPA and NAC reagents. Experiments were also conducted on a solution of $\mathrm{NH}_{4} \mathrm{Cl} 100 \mu \mathrm{M}$ in order to detect possible interferences of the reducing conditions on the ammonium derivatization. As shown in Figure 2 , best results were obtained at $\mathrm{pH} 5$ and $\mathrm{pH} 6$. In fact, in both cases conversion of nitrate to ammonium occurred and high values of fluorescence for ammonium were detected, resulting in good sensitivity under these conditions. According to data obtained, reduction of nitrate is much less efficient at $\mathrm{pH} 7$ or when basic carbonate and borate buffers are employed, also probably because of the evaporation of $\mathrm{NH}_{3}$ which is predominant at neutral/basic $\mathrm{pH}$. Regarding the acidic conditions selected for the study, it appears that in the case of $\mathrm{HCl} 2.5 \mathrm{M}$ there is no substantial difference between the blank values and those of nitrate and ammonium, while in the case of $\mathrm{H}_{2} \mathrm{SO}_{4}$ data related to ammonium derivatization are very low. The MES buffer $(0.1 \mathrm{M}, \mathrm{pH} 6)$ was selected for the following experiments, given the higher value provided by the test on the ammonium solution revealing a higher sensitivity for this $\mathrm{pH}$ level. The subsequent experiments were mainly aimed to optimise the conditions for the enhancement of the conversion of nitrate to ammonium.

A kinetic test was carried out in order to select the best time condition for the reduction of nitrate with zinc powder (more efficient than zinc granules). As shown in Figure 3, after 30 min about $90 \%$ of the nitrate is reduced to ammonium indicating that this could represent a good time condition for the proposed procedure. The influence of $\mathrm{Zn}$ powder quantity on the reduction rate at the selected conditions $\left(30^{\circ} \mathrm{C}, 30 \mathrm{~min}\right)$ was also studied. Calibration curves obtained with 10, 20 and $30 \mathrm{mg}$ of $\mathrm{Zn}$ are shown in Figure 4. Tests performed with $10 \mathrm{mg}$ of powder showed that there is a loss of linearity at concentrations higher than $50 \mu \mathrm{M}$ indicating also that, in this case, contact surface is not large enough to provide efficient conversion of nitrate to ammonium. At the same time, experiments carried out with $30 \mathrm{mg}$ of powder, showed 
a worsening of the $\mathrm{R}^{2}$ value probably due to an interference caused by the excess of solid particles in the suspension. For this reason, $20 \mathrm{mg}$ was selected as the best compromise for the procedure. Finally, influence of an increase of the reaction temperature was also assessed (up to $40^{\circ} \mathrm{C}$, the maximum heating capacity of most microplate readers/shakers), with no significant improvements, and $30^{\circ} \mathrm{C}$ was therefore selected for the optimized protocol.

\subsection{Interferences}

The interference of various major anions and cations that could be found in compost extract samples was investigated. More specifically, $\mathrm{K}_{2} \mathrm{SO}_{4}, \mathrm{KH}_{2} \mathrm{PO}_{4}, \mathrm{Na}_{2} \mathrm{CO}_{3}, \mathrm{MgCl}_{2}, \mathrm{NaCl}, \mathrm{NaBr}$ and $\mathrm{CaCl}_{2}$ were selected for the study. Other less common redox active anions (low redox potential/high reducing ability) such as $\mathrm{HPO}_{3}{ }^{2-}, \mathrm{SO}_{3}{ }^{2-}$ and $\mathrm{C}_{2} \mathrm{O}_{4}{ }^{2-}$ have also been included in these interferences tests. The analytical protocol was applied to pure solutions of the cited salts or anions at a concentration of $2 \mathrm{mM}$, giving a response not significantly different from the blank. Moreover, tests were also performed on mixtures of $\mathrm{NaNO}_{3} 100 \mu \mathrm{M}$ and selected interfering compounds in order to compare results with those given by the pure $\mathrm{NaNO}_{3}$. Results showed that the salts tested did not interfere up to at least $2 \mathrm{mM}$.

Experiments conducted on a standard solution of $\mathrm{NaNO}_{2} 100 \mu \mathrm{M}$ revealed that nitrite shows the same behavior as nitrate, being reduced to ammonium by $\mathrm{Zn}$ at the same $\mathrm{pH}$ conditions. Anyway, analysis performed by ion-exchange chromatography on the samples confirmed the already expected absence of nitrite in the aqueous compost extracts. Interferences from nitrite should therefore be negligible in this type of environmental samples, but has to be considered (separate quantification by Griess reagent) if the method is applied to other samples with significant nitrite concentrations.

\subsection{Analytical features}

The assessed procedure was validated in terms of sensitivity, linearity, precision and accuracy. The limit of detection (LOD) was calculated from the residual standard deviation of the regression (linearity study method). More specifically, LOD was evaluated as follows: $\mathrm{LOD}=3 \mathrm{~s} / \mathrm{b}$ where $s$ is the standard deviation (SD) of the a-intercept and b the slope of the calibration curve. LOD is $1.30 \mu \mathrm{M}\left(0.08 \mathrm{mg} \mathrm{L}^{-1}\right)$. It is interesting to note that detection limit is almost an order of magnitude smaller than the LOD estimated by Murray et al. [22], for their procedure using zinc reduction and a spectrophotometric method $\left(0.5 \mathrm{mg} \mathrm{L}^{-1}\right)$.

The calibration curve $(I=11.10 \mathrm{C}+316.2 ; \mathrm{I}=$ fluorescence intensity (arbitrary units), $\mathrm{C}=$ nitrate concentration $(\mu \mathrm{M}))$ was linear up to $100 \mu \mathrm{M}$ with a correlation coefficient of 0.9941 , resulting in a large enough linear dynamic range for our analytical purposes (4.5-100 $\mu \mathrm{M})$. Relative 
standard deviations were assessed on a $5 \mu \mathrm{M}(\mathrm{RSD}=14.3 \%)$ and on a $50 \mu \mathrm{M}(\mathrm{RSD}=4.2 \%)$ nitrate standards ( $n=10$ replicates) indicating a good repeatability for both concentration levels.

\subsection{Comparison with other microplate methods for nitrate determination}

The microplate format is an ideal tool for routine analysis when a large number of samples has to be analyzed in a short time (typical case for ammonium or nitrate determination in aqueous samples). All methods adapted in microplate are based on the reduction of nitrate to nitrite and subsequent spectrophotometric measurements after reaction with Griess reagent. Reduction of nitrate to nitrite has been performed by various methods: copperised cadmium granules [25] or pins [15], vanadium (III) [26] or enzymatic reduction [27]. Global reaction times are a bit longer with these methods (60-90 min at room temperature) compared to our method (40 min). The main advantage of these spectrophotometric techniques is the low detection limits (12-20 $\mu \mathrm{g} \mathrm{L}^{-1}$ ) which are 4 to 6 times lower than our spectrofluorimetric method. However, these methods also have limitations for compost analysis: i) the main reduction methods still use cadmium which is highly toxic; ii) complex and colored samples such as compost extracts will display strong matrix effects using spectrophotometric techniques [28], making fluorimetric measurements highly desirable; iii) determination of nitrate and ammonium $\left(\mathrm{NH}_{4}{ }^{+} / \mathrm{NO}_{3}{ }^{-}\right.$ratio is one of the principal nitrogen-based indicators of compost maturity) requires two sets of detection reagents if the Griess reagent is used, while our methodology easily provides quantification for both analytes (with or without reduction step).

Similarly, nitrate determination using nitration of resorcinol and spectrophotometric measurement is not suitable for this type of analysis, as it uses pure sulfuric acid (not compatible with microplates) and displays strong interferences due to sample color (own experiments, data not shown).

Overall, our fluorimetric method seems more adapated to compost extract analysis in the microplate format than methods based on spectrophotometry.

\subsection{Quantification of nitrate ion and method validation in aqueous compost extracts}

Nitrate was quantified by means of the assessed procedure in twenty-five aqueous extracts of compost of various sources, using the external calibration method. Sample dilution represents a critical point of the whole analytical protocol because the highly-colored matrix can heavily disturb spectroscopic measurements. Moreover, dilution is required in order to match the defined calibration range both for ammonium and nitrate. A comparison between the slope of calibration curves obtained by means of external calibration and multiple standard addition methods for some selected samples was exploited in order to select a dilution ratio able to minimize the interferences given by matrix, but still able to detect nitrates and ammonium. A 
5-fold dilution was adopted for A samples and a 50-fold one for B samples. Nitrate concentration was quantified in a range included between $2.0 \pm 0.1$ and $90 \pm 10 \mathrm{mg} \mathrm{L}^{-1}$. These twenty-five samples were also chosen for comparison purposes between ion-exchange chromatography and microplate measurements with the developed procedure. As shown by Figure 5 , a good correlation $\left(\mathrm{R}^{2}=0.9127\right)$ was found between the two data sets, and a very weak intercept value with regard to the studied concentration range sets. The slope reveals a slight underestimation of data obtained by the microplate method, probably due to residual matrix effects of these compost samples. A higher dilution rate would have improved these results, but was not possible because most samples would have too low concentrations for proper nitrate or ammonium quantification. Results are still satisfactory for a field test tool, which is aimed to assess the evolution of nitrate concentration during the composting process and which mainly requires a good correlation between the measurements and the actual concentrations in the compost samples.

\section{Conclusions}

In this study, we presented the assessment and validation of a new analytical method using the microplate format for the determination of nitrate ion in aqueous compost extracts. Optimization work allowed to obtain fast and stable responses by employing a small quantity of a non-toxic metal (zinc) for the reduction. Nitrate reduction with zinc (mainly studied for the reduction of nitrate to nitrite, much less to the final ammonium reduction), was coupled with a fluorimetric detection method, offering several advantages such as lower detection limits (an order of magnitude lower than the spectrophotometric method described with zinc reduction [22], especially using the microplate format) and less interferences due to complex and colored samples such as compost extracts. It also potentially enables the easy determination of both nitrate and ammonium ions with a single set of detection reagents (with or without the reduction step), which is highly valuable as the $\mathrm{NH}_{4}{ }^{+} / \mathrm{NO}_{3}{ }^{-}$ratio is one of the principal nitrogen-based indicators of compost maturity. Besides, no strong acids are used in this method, on the contrary of other frequently used analytical methods for nitrate [10,12]. Preventing the use of strong acids or toxic metals and reagents is highly desirable for this type of analytical method which is meant to be used directly on composting platforms by non-expert technicians. Only a small volume of sample is required for the analysis and the whole procedure is completed in about 40 min with the possibility to analyze several extracts at the same time thanks to the microplate instrumentation. Validation showed that the proposed procedure is sensitive, precise and with a good level of accuracy. For all these reasons, the method is a good candidate for routine analysis of nitrate in aqueous compost extracts, either in a traditional laboratory or directly in composting platforms. A simple on-site compost extraction with a 
modified coffee machine is currently under evaluation in our laboratory in order to reach a full on-site analytical procedure.

\section{Acknowledgment}

This work was financially supported by the French Environment and Energy Management Agency (ADEME) through the programme "ODIAMAC" [Convention n¹506C0034].

\section{Literature cited}

[1] P. Kaiser, Analyse microbiologique des composts in :Rapport du colloque international : Composts, amendement humique et organiques (16-17 Novembre 1981), Ed. Paris : ISG Avenir 1981., pp. 43-71.

[2] M. De Bertoldi, Compost quality and standard specifications: European perspectives in: Harry A.J., Hoitink and Harold MIKeener ed. (The Ohio State University), Science and Engineering of Composting: Design, Environmental, Microbiological and Utilization Aspects, 1993, pp. 523-535.

[3] B. Leclerc, Guide des matières organiques, Collection Guide Technique de I'Institut Technique de l'Agriculture Biologique (ITAB), Tome 1, 2ème édition, 01/2001.

[4] A. Shiralipour, D. B. McConnel, W. H. Smith, Uses and benefits of MSW compost: a review and an assessment. Biomass Bioenerg., 3 (1992) 267-279.

[5] K. Das, H. M. Keener, Moisture effect on compaction and permeability in composts, J. Env. Eng.,123 (1997), 275-281.

[6] Y. Eklind, H. Kirchmann, Composting and storage of organic household waste with different litter amendments. I : carbon turnover. Bioresource Technol., 74 (2000), 115-124.

[7] Stoffella, P. J., \& Kahn, B. A. (Eds.),. Compost utilization in horticultural cropping systems. CRC press, LLC, Florida, 2001. 
[8] Council Directive 91/676/EEC of 12 December 1991 concerning the protection of waters against pollution caused by nitrates from agricultural sources. Official Journal L 375, (1991), 1-8.

[9 N. Raikos, K. Fytianos, C. Samara, V. Samanidou, Comparative study of different techniques for nitrate determination in environmental water samples, Fresen Z Anal. Chem., 331 (1988), 495-498.

[10] J-Z Zhang, C. J. Fischer, A simplified resorcinol method for direct spectrophotometric determination of nitrate in seawater, Mar. Chem., 99 (2006), 220-226.

[11] A. H. Miguel, R. D. Braun, Fluorimetric analysis of nitrate in real samples, J. Chem. Educ., 51 (1974), 682-683.

[12] S.Biswas, B. Chowdhury, B. C. Ray, A novel spectrofluorimetric method for the ultra trace analysis of nitrite and nitrate in aqueous medium and its application to air, water, soil and forensic samples, Talanta, 64 (2004), 308-312.

[13] C. D. Stalikas, C. N. Konidari, C.G. Nanos, Ion chromatographic method for the determination of nitrite and nitrate by post-column indirect fluorescence detection, J. Chromatogr. A, 1002 (2003), 237-241.

[14] S. Motomizu, H. Mikasa, K. Toei, Fluorimetric determination of nitrate in natural waters with 3-amino-1,5-naphtalenedisulfonic acid in a flow-injection system, Anal. Chim. Acta, 193 (1987), 343-347.

[15] J. D. Crutchfield, J. H. Grove, A new cadmium reduction device for the microplate determination of nitrate in water, soil, plant tissue, and physiological fluids, J. AOAC Int., 94 (2011), 1896-1905.

[16] J. Wu, Y. Hong, F. Guan, Y. Wang, Y. Tan, W. Yue, M. Wu, L. Bin, J. Wang, J. Wen, A rapid and high-throughput microplate spectrophotometric method for field measurement of nitrate in seawater and freshwater, Sci Rep-UK, 6 (2016), 1-9.

[17] F. Robert-Peillard, E. Palacio Barco, M. Ciulu, C. Demelas, F. Théraulaz, J-L. Boudenne, B. Coulomb, High throughput determination of ammonium and primary amine compounds in environmental and food samples. Microchem. J., 133 (2017), 216-221. 
400 [18] B. Coulomb, F. Robert-Peillard, E. Palacio, R. Di Rocco, J-L. Boudenne, Fast microplate

401

402

403

404

405

406

407

408

409

410

411

412

413

414

415

416

417

418

419

420

421

422

423

424

425

426

427

428

429

430

431

432

433

434

435 assay for simultaneous determination of thiols and dissolved sulfides in wastewater, Microchem. J., 132 (2017), 205-210.

[19] F. Robert-Peillard, C. Chottier, B. Coulomb, J-L. Boudenne, Simple and ultrasensitive method for spectrofluorimetric determination of trace resorcinol, Microchem. J., 122 (2015), 59.

[20] F. Robert-Peillard, J-L. Boudenne, B. Coulomb, Development of a simple fluorescencebased microplate method for the high-throughput analysis of proline in wine samples, Food Chem., 150 (2014), 274-279.

[21] J. C. Fanning, The chemical reduction of nitrate in aqueous solution, Coordin. Chem. Rev., 199 (2000), 159-179.

[22] E. Murray, E. P. Nesterenko, M. McCau, A. Morrin, D. Diamond, B. Moore, A colorimetric method for use within portable test kits for nitrate determination in various water matrices, Anal Methods-UK, 9 (2017), 680-687.

[23] L. Merino, Development and validation of a method for determination of nitrite/nitrate in foodstuffs and water after zinc reduction, Food Anal. Methods, 3 (2009), 212-220.

[24] P. Ellis, A. Shabani, B. Gentle, M. Mckelvie, Field measurements of nitrate in marine and estuarine waters with a flow analysis system utilizing on-line zinc reduction, Talanta, 84 (2011), 98-103.

[25] X. Tu, B. Xiao, J. Xiong, X. Chen, A simple miniaturised photometrical method for rapid determination of nitrate and nitrite in freshwater, Talanta, 82 (2010), 976-983.

[26] E. García-Robledo, A. Corzo, S. Papaspyrou, A fast and direct spectrophotometric method for the sequential determination of nitrate and nitrite at low concentrations in small volumes, Mar. Chem., 162 (2014), 30-36.

[27] S. Ringuet, L. Sassanoa, Z. I. Johnson, A suite of microplate reader-based colorimetric methods to quantify ammonium, nitrate, orthophosphate and silicate concentrations for aquatic nutrient monitoring, J. Environ. Monit. 13 (2011), 370-376. 
437 [28] A. Simeonov, M.I. Davis, Interference with fluorescence and absorbance, Assay Guidance 438 Manual [Internet] (2015), Available from:

439 https://www.ncbi.nlm.nih.gov/books/NBK343429/pdf/Bookshelf NBK343429.pdf

440

441

442 Figure captions

443 Figure 1. Proposed protocol for nitrate determination; Figure 2. Influence of the $\mathrm{pH}$ of the 444 reduction step on the fluorescence intensity response of standard solutions after reduction and 445 derivatization with OPA/NAC (zinc granules, $1 \mathrm{~h}$ reduction time, $\mathrm{n}=2$ ). Figure 3. Influence of 446 the time of the reduction step on the fluorescence intensity response of standard solutions after 447 reduction and derivatization with OPA/NAC (20 mg zinc powder, $n=2)$. Figure 4. Calibration 448 curves $(0-100 \mu \mathrm{M})$ depending on the quantity of zinc powder used for the reduction step (30 449 min reduction time, $n=2)$. Figure 5. Comparison between microplate method and ion-exchange 450 chromatography $(n=2)$.

451

\section{Step 1: reduction}

$$
\mathrm{NO}_{3}^{-} \stackrel{\mathrm{Zn}}{\longrightarrow} \mathrm{NH}_{4}^{+} \mathrm{NH}_{3} \text { (function of } \mathrm{pH} \text { ) }
$$

Step 2: derivatization

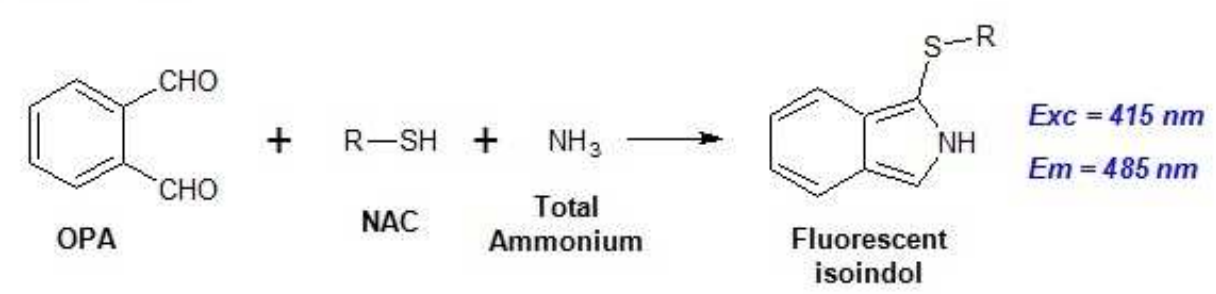




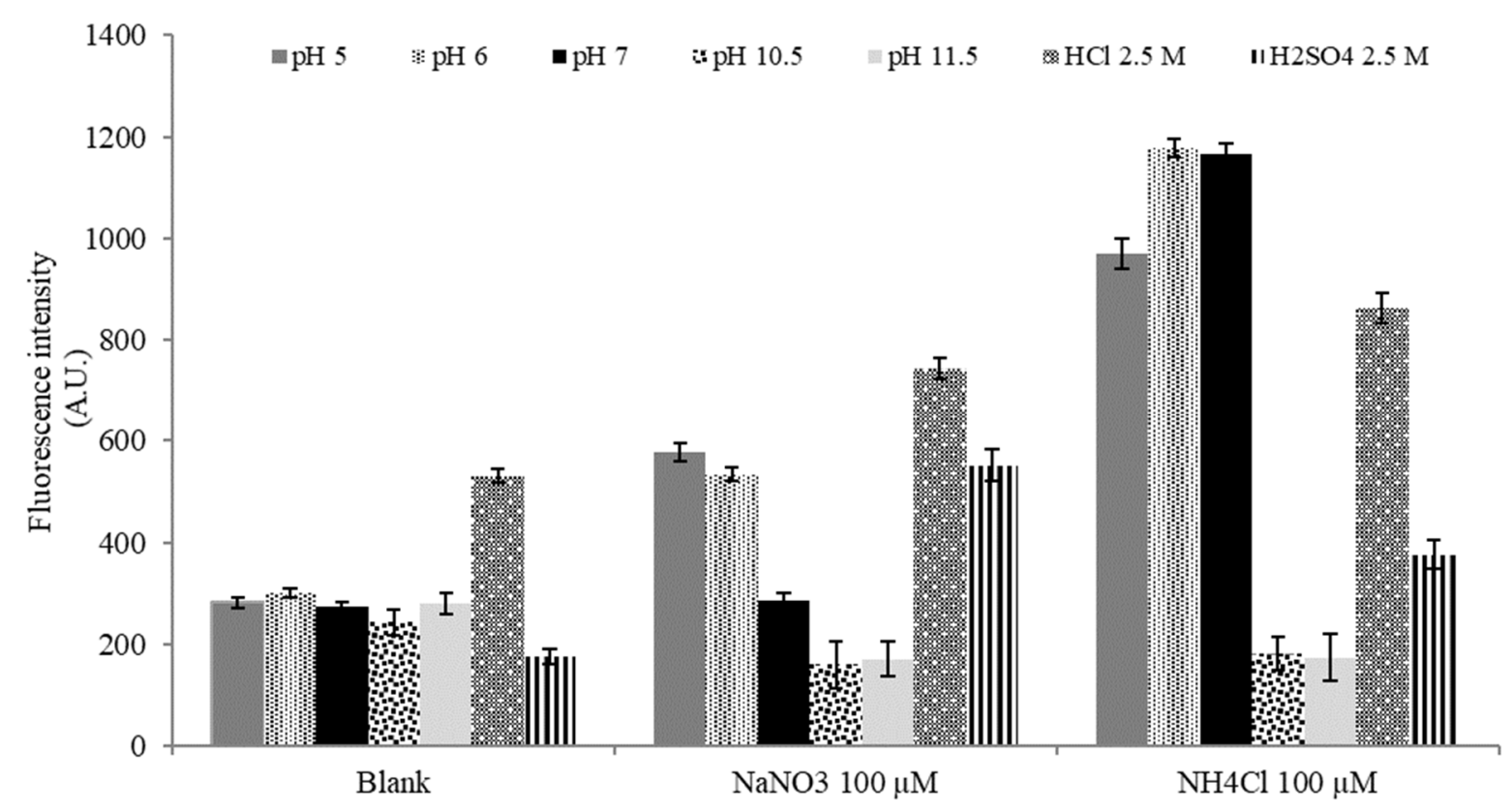

453

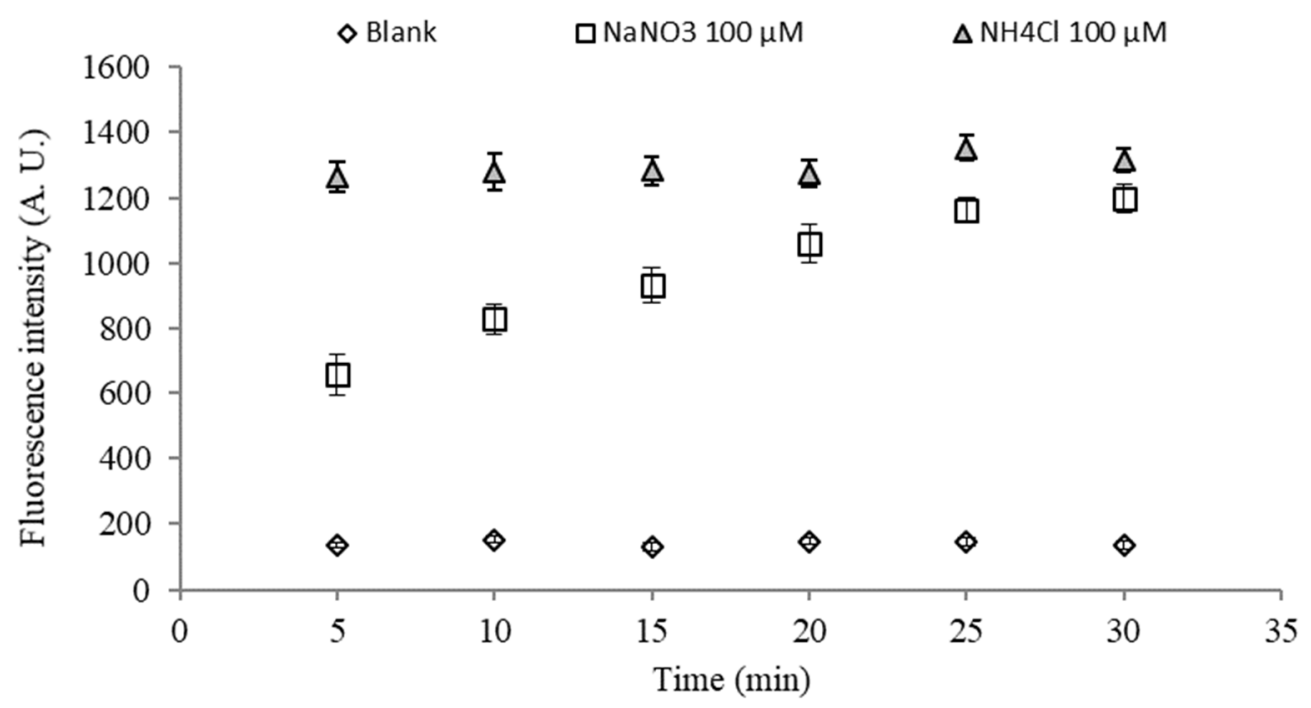

454

455 
$10 \mathrm{mg}$

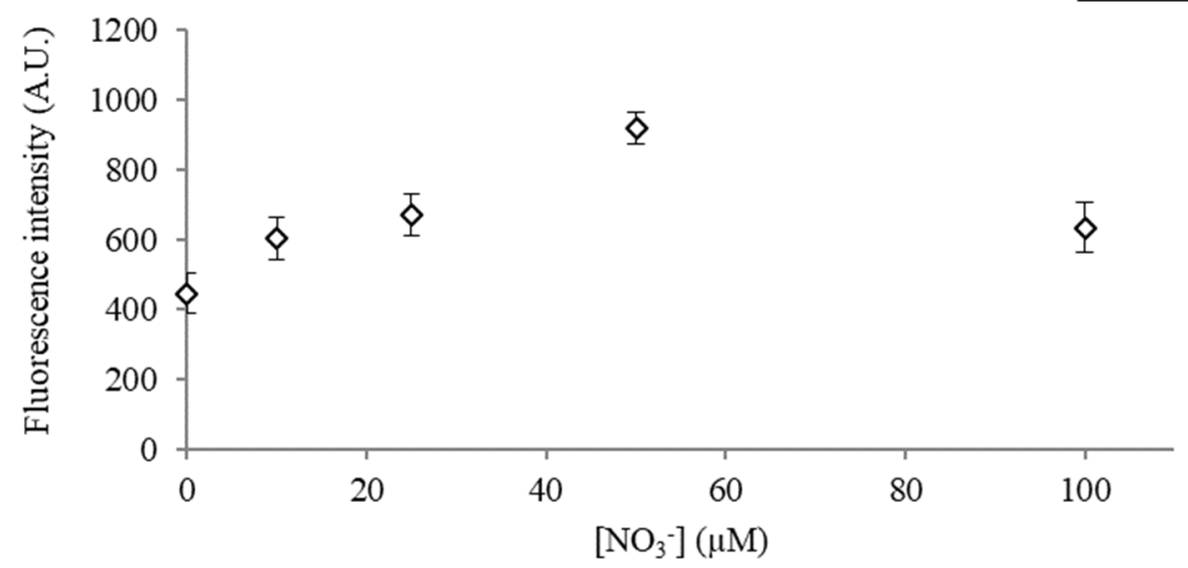

456

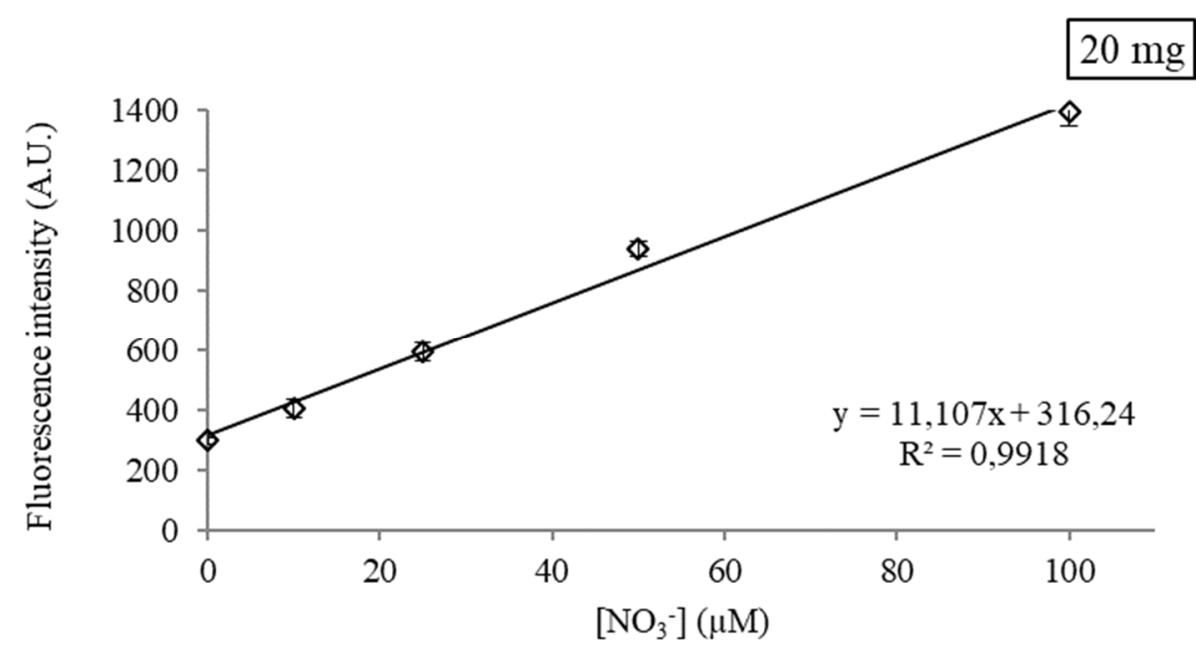

457

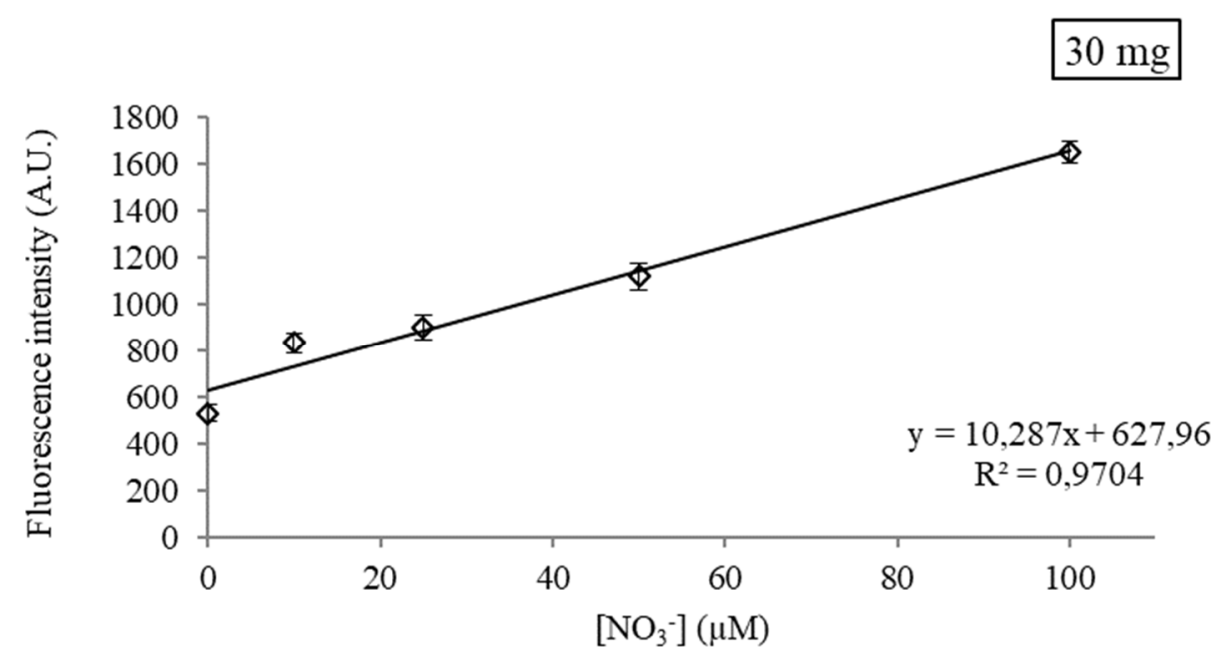

458 


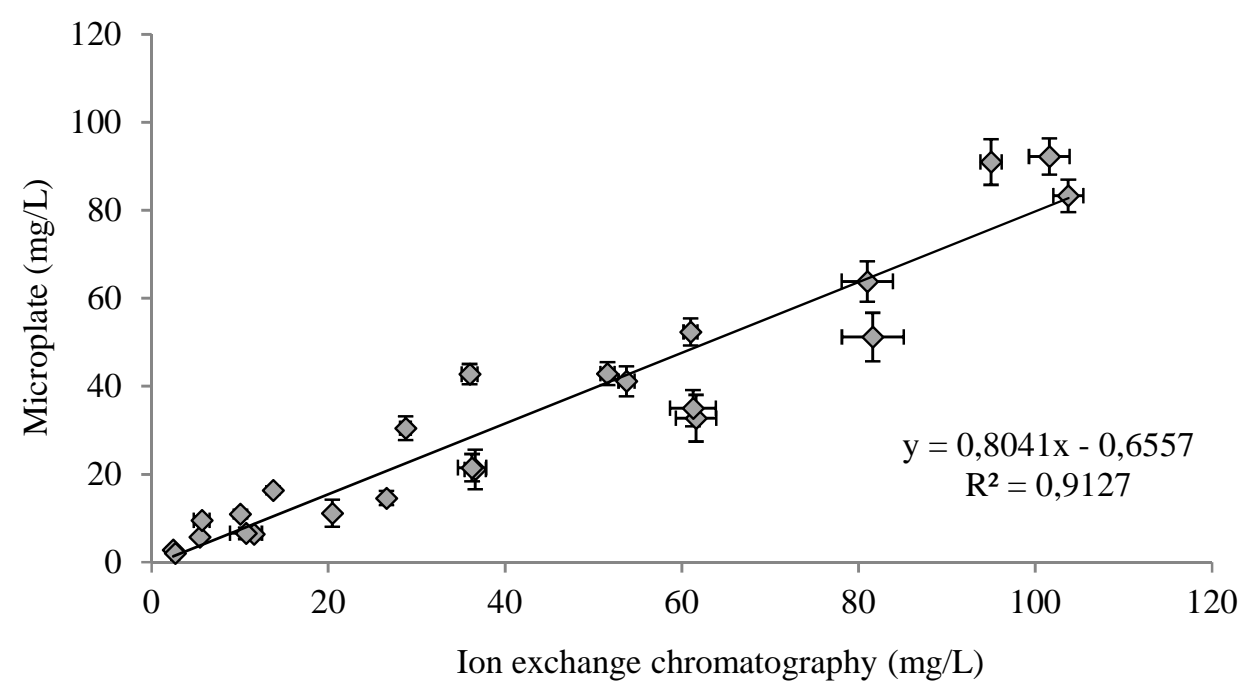

